\title{
The Use of Nuclear Radiation in Combustion Research
}

\author{
MARTIN E. GLUCKSTEIN, ${ }^{1}$ RICHARD B. MORRISON, ${ }^{2}$ and JOHN V. NEHEMIAS ${ }^{3}$
}

Engineering Research Institute, University of Michigan, Ann Arbor, Mich.

The interaction of nuclear radiation with fuel-oxidant systems may cause increased rates of chemical reaction. Based on simple models for the interactions and the controlling rate processes, it is shown that change in over-all reaction rate should be dependent upon the energy and activity of the radiation source. Only beta and alpha emitters are considered since, for gas phase reactions or for reactors of relatively small size, they are the more efficient sources. The problems involved in the use of radioactive materials in combustion research are discussed and, in particular, criteria for compatible design are established. The possible application of this technique to improve the performance of combustion devices is discussed in the light of the difficulties and results of experimental work in this field.

\section{Introduction}

$\mathbf{T}$ HIS paper presents some of the experiences of the authors in the use of nuclear radiation in combustion research, some pertinent experimental design considerations, and possible application to combustion devices. Discussion will be limited to the problems of design, handling, and application of the radioactive materials, since some of the results have been reported elsewhere $(1,2){ }^{4}$

Programs of this type gained impetus under the fission products utilization program of the United States Atomic Energy Commission. The use of radiation from these materials to promote chemical reactions, including those in combustion devices, has been considered. However, these studies may also offer an opportunity to gain insight into the fundamental processes occurring in combustors.

Only alpha and beta sources will be considered in this paper. Generally speaking, gamma radiation in the Kev and Mev range is too penetrating to be useful in work of this type, but must be considered since it is most difficult to sbield and hence a primary health physics problem.

\section{Discussion}

To determine the effect nuclear radiation might have on combustion systems, it is first necessary to consider some of the details of the possible mechanism and kinetics of oxidation reactions and the mechanism of the interaction of radiation with the reaction system. If one considers the oxidation of a hydrocarbon, there is abundant evidence that the reaction does not proceed according to the over-all stoichio-

Presented at the Nuclear Engineering and Science Congress, Cleveland, Ohio, Dec. 12-16, 1955.

${ }_{1}$ Research Associate, Aircraft Propulsion Laboratory.

${ }^{2}$ Associate Professor of Aeronautical Engineering and Supervisor, Aircraft Propulsion Laboratory. Mem. ARS.

${ }_{3}$ Research Associate and Health Physicist, Fission Products Laboratory.

${ }^{4}$ Numbers in parentheses indicate References at end of paper. metric equation, but through a series of consecutive or simultaneous reactions involving free radials and atoms, such as $\mathrm{O}, \mathrm{OH}, \mathrm{CH}_{3}, \mathrm{C}_{2} \mathrm{H}_{5}$; and the various partial oxidation products of the hydrocarbon, such as $\mathrm{CO}$, aldehydes, ketones; and transitory materials, such as peroxides; as well as the original materials $(4,6,7)$. It is sufficient for the development of a consistent physical model to consider the reactions in general, without recourse to any specific system.

For any chemical reaction

$$
M+N \rightarrow M N^{*} \rightarrow M N
$$

where $M N$ is the product and $M N^{*}$ the activated complex, the rate of reaction may be expressed as

$$
r=k_{r} C_{M} C_{N}
$$

where $r$ is the rate of formation of $M N ; C_{A}, C_{B}$; the concentration of $M$ and $N$ and $k_{r}$, a reaction rate "constant" in consistent units. The constant $k_{r}$ is usually expressed by the Arrhenius equation as

$$
k_{r}=A \exp \left(-E_{T} / R T\right)
$$

where $A$ is the "frequency factor" and $\exp \left(-E_{T} / R T\right)$ is the fraction of molecules in the given system of energy equal to or greater than $E_{T}$. The value of the constant $A$ is determined from the partition functions for $M, N$, and $M N^{*}$ and is a function of the temperature and the atomic or molecular constants associated with the particular species involved in the reactions. One may, however, vary the fraction of active molecules (i.e., those of energy equal to or exceeding $E_{T}$ ) by providing an external source of high energy molecules or by generating them within the system. One method of generating arditional active species is to subject the reaction mass to ionizing (nuclear) radiation.

The specialized development of exact relationships for the interaction of radiation and matter is beyond the scope of this paper. It is only necessary to consider the gross effect of such interactions. Experimentally, it has been shown that alpha, beta. or gamma radiation, when passing through a gaseous medium, induces ionization and reactions of the type

$$
\mathrm{O}_{2} \rightleftharpoons 2 O^{*} \text {. }
$$

or generally

$$
M N \rightleftharpoons M^{*}+N^{*} .
$$

The asterisk indicates that the energy of the species generated by the interaction is higher than energy which is associated with the thermally produced species. On the average, each interaction expends 33 electron volts to form an ion pair (such as $M^{*}+N^{*}$ above). Since the activation energy $E_{T}$ for most reactions is of the order of $10-100 \mathrm{~K} \mathrm{cal} / \mathrm{mole}$ ( 0.42 to $4.2 \mathrm{er}$ per molecule), the value of $33 \mathrm{ev}$ is in excess of the activation energy and, therefore, the species produced by the interaction are active insofar as reaction is concerned. 


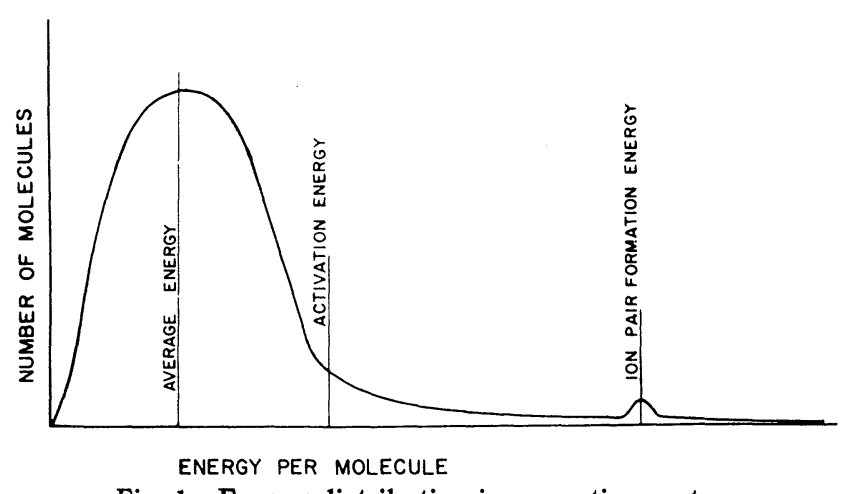

Fig. 1 Energy distribution in a reacting system

Fig. 1 shows diagrammatically the energy diagram for gaseous reaction system in the presence of an ionizing source.

The effect of radiation on the reaction rate constant may be expressed mathematically as

$$
k_{r}{ }^{\prime}=A\left[\exp \left(-E_{T} / R T\right)+f\right] .
$$

where $f$ is the fraction of radiation induced active species. The ratio of the reaction rates with and without radiation should be

$$
r^{\prime} / r=1+\exp \left(E_{T} / R T\right) \cdot f
$$

To evaluate $f$ it is necessary to know the energy, type of the radiation, the total activity, and a factor based on the geometry of the systems. The value of $f$ will be given by

$$
f=\phi(C E / 33)\left(M \times N_{0}\right)^{-1} \times 3.7 \times 10^{10} .
$$

where $C$ is the activity of the source in curies; $E$ its energy in electron volts; $M$ the molar flow rate, mole-sec ${ }^{-1} ; N_{0}$ Avogradro's number; and $\phi$ factor for geometry, secondary radiation, and other factors mentioned above.

As an example consider an experimental combustor $3 \mathrm{~cm}$ in diam and $30 \mathrm{~cm}$ long, operated at one atmosphere pressure. It is desired to locate the radioactive material in the wall of this reactor. The flow rate of fuel and oxidant is 0.01 mole per sec and it may be assumed to have the same absorptive properties as air. The source is to be a $1-\mathrm{Mev}$ beta emitter. It has been calculated from Equation [4] that $f$ must have a value equal to or greater than $10^{-5}$ to be effective in accelerating combustion. To compute $f$, one must first evaluate $\phi$. For $1 \mathrm{Mev}$ beta radiation, the range is about $300 \mathrm{~cm}$ in air. To estimate $\phi$, it is assumed that the active species formed have a life of 1 microsec and therefore only interactions in the reactor volume need be considered. Since the diameter of the reactor is 1 per cent of the range, at most 1 per cent of the primary radiation is effective. However, due to the spherical distribution of the radiation, some particles will pass out the ends of the reactor and be ineffective. Neglecting reflection and secondary radiation, $\phi$ will be about $10^{-3}$. From Equation [5], $C=1.3 \times 10^{3}$ curies.

Consider the same design using alpha radiation of about 5 Mev. For this radiation, the range is about $3 \mathrm{~cm}$ and $\phi$ will be at least 0.1. From Equation [5], $C$ will be about 3 curies.

One may not conclude that for this application the alpha source would be more desirable than the beta. The ultimate selection of the source will depend on the availability, handling difficulties, chemical stability, hazard, and costs. Of these, those factors which affect health and safety are most important. Some of the health physics aspects of this type of work are presented in the next section.

\section{Health Physics}

Personnel working with radioactive materials are exposed to two distinct types of hazards: (a) external radiation and (b) contamination. It is important that these two types of radiation hazards be separately evaluated for each proposed experiment using radioactive materials.

\section{A External Radiation}

Serious instances of injury due to external radiation occurred in the early days of work in this field. Within 30 days of the discovery of $x$-rays by Roentgen in 1896 , one of his co-workers reported hand dermititis so acute that medical aid was required. Another early radiation injury involved Henri Becquerel himself. Several years after his discovery of radioactivity he had occasion to carry a tube containing a radium salt in his vest pocket for several days. An ugly red lesion developed on his abdomen which did not heal for several months and left a permanent scar.

The absorption of ionization radiation by living tissue causes injury to individual living cells. The injury is manifested as the malfunction or death of some of the irradiated cells, which, according to the severity of the exposure, may subsequently cause clinical symptoms or death of the organism. However, even a lethal dose of radiation causes the victim no immediate pain or discomfort. Death does not follow immediately, but results from buildup of degenerative toxins and lowered resistance to trauma and infection.

Although the cellular destruction caused by ionizing radiation is characteristically similar for all known types of ionizing radiation, the degree of localization, and thus the severity, vary according to the rate at which the type of radiation in question is absorbed. External alpha radiation, for instance, which is the only radiation emitted by polonium-210, is totally absorbed in the loamy, surface layer of epithelial tissue. Serious radiation injury from an external exposure to alpha radiation is quite unlikely.

Beta radiation, which is the only radiation emitted by palladium-109, penetrates several millimeters of tissue. Severe blistering and burns, which heal very slowly, result from local overexposures to external beta radiation. Gross effects on total metabolism from external beta radiation can be observed only if a large part of the body is exposed or the exposure is very large.

Gamma radiation, which is emitted by gold-198 in addition to beta radiation, produces effects throughout the body because of the highly penetrating nature of the radiation. Gross metabolic effects, such as reductions in white blood cell levels, rather than localized injury, result from severe overexposure.

The risk of personal injury from external radiation may be minimized by judicious manipulation of three physical parameters: distance, time, and shielding.

A radioactive material emits its radiation in all directions. As the distance from the source increases, the radiation flux decreases. For a point source, this rate of decrease is inversely proportional to the square of the distance. Radiation exposure to personnel can be reduced most simply by minimizing operations which require approaching the radioactive material. The use, when possible, of tongs and other remote control manipulators exemplifies this principle.

When it is essential that an operation be performed in such a way that high exposure rates are experienced by personnel, exposure can obviously be best minimized by expediting the operation in every possible way to the time spent in the intense radiation field.

When the optimum use of distance and time cannot reduce exposures to a tolerable level, the use of shielding materials becomes necessary. As ionizing radiation penetrates matter, interactions occur, energy is lost, and total intensity is reduced. The interposition of matter (such as water, concrete, lead) between the radioactive material and operating personnel thus results in reduced radiation levels.

Alpha particles may be completely absorbed by a sheet of heavy paper, beta particles by a few centimeters of lucite. Gamma radiation, on the other hand, is absorbed exponentially. That is, if a certain thickness reduces the radiation from 100 to 10 , twice that thickness would reduce it from 100 to 1 . Thus no thickness of shielding will completely absorb 
gamma radiation. It becomes necessary to think in terms of radiation levels to acceptable values.

In the ideal case of absorption of a perfectly collimated beam of radiation, the degradation of energy, scattering, and production of secondary radiation can be ignored, as any interaction of these types would completely remove the interacting particle or photon from consideration. In practical cases, however, the build-up of secondary radiation is an important consideration.

The gamma radiation intensity at a point in an absorber consists of primary gamma photons, the photons of degraded energy resulting from Compton scattering, secondary electrons (photoelectrons, Compton electrons, and electron pairs), and the electromagnetic radiation produced by the absorption of these electrons. The secondary radiation is, in general, more rapidly attenuated than the primary gamma radiation.

The radiation intensity $I$ at a point behind a shield of thickness $X$ is computed from the relationship

$$
I=I_{0} \beta^{-\mu X} \text {. }
$$

where $I_{0}$ is the radiation intensity at the same point with no shielding present, $\beta$ is the buildup factor, and $\mu$ the absorption coefficient. $\beta$ and $\mu$ can be evaluated from the literature $(3,5)$. These two quantities depend upon absorber material, thickness, and radiation energy.

\section{B Contamination}

When a radioactive element enters the body, it is distributed, metabolized, and utilized in the same manner as the same element would be in the nonradioactive state. When these processes lead to incorporation into the body structure by deposition in the bone or by other means, localized internal radiation damage may ensue. As in the case of external radiation injury, no pain or discomfort is felt by the victim until some time after the ingestion. This delay in the appearance of observable symptoms renders the task of diagnosing the ultimate cause and evaluating potential injury from an exposure exceedingly difficult.

Radioactive material may enter the body by three main routes: inhalation, ingestion, and injection. Airborne particles or radioactive gases may be inhaled. Radioactive material unconsciously or absent-mindedly transferred to food, cigarettes, or pencils may find its way into the body through the mouth. The accidental puncturing of protective clothing and the skin during an experiment may inject radioactivity directly into the blood stream.

The mechanism of injury is the same whether the radiation is external or internal. The radiation characteristics which determine the degree of internal radiation hazard are quite different from those previously discussed for external radiation.

Alpha radiation is completely absorbed in a small volume of tissue, leading to severe localized tissue damage, sarcoma, and other related injuries. If an equal amount of beta radiation energy is absorbed in the body, it would be distributed throughout a much larger tissue volume. Tissue damage in this case is more diffuse but still localized. Internal gamma radiation would penetrate still further and would be expected to produce little local injury-only gross total body radiation damage.

The risk or personal injury to inhaled or injected radioactive materials can be minimized by careful experimental design, continuous radiological monitoring, and good housekeeping procedures.

The initial design of an experiment must take into account the degree of contamination involved. Good experimental design should minimize the possibility of incidents which could speed radioactive contamination, as well as include safe procedures for use in the event such a mishap occurs.

Electronic radiation monitoring devices can be kept in continuous operation throughout an experiment. They can sound the alarm when a predetermined "safe" level of radioactivity is exceeded and set emergency procedures into operation. A further radiological check of workers' hands, feet, and clothing as they leave the laboratory protects the workers and prevents the spread of radioactive material outside the laboratory.

The procedures involved in keeping a laboratory radiologically clean are mostly common sense. No dust or dirt are allowed to accumulate. Waste is disposed of before large amounts pose a radiation problem. Smooth, easily cleaned surfaces are used where possible. Otherwise, cheap and removable surfacing material is used.

\section{Special Design Considerations}

The most important single factor in the design of equipment to utilize nuclear radiation in combustion research is that the experimental procedures be compatible with the requirements of radiological safety. It is necessary that all stages of planning and execution of the research program be made with the assistance of competent radiological safety personnel, since the research worker is often not able to objectively analyze the potential radiological hazard in a particular design or operation.

The initial step in equipment design is to prepare a preliminary sketch of the equipment showing source location and other pertinent details, and to list the important assembly and data taking operations. It is then necessary to calculate the approximate activity required for various possible types of sources, as shown in the Discussion. Each potential source material must then be examined in detail. It is first necessary to ascertain whether the required activity can be obtained, and at what cost. The half life may be a factor from both the experimental and health standpoint. It is important that the decay scheme of the isotope be examined to be certain that the radioactivity of the daughter products of the primary source are not neglected. Experimentally, it is desirable that the half life of the source be long compared to the time required for a data run, so that the activity is nearly constant throughout the operation. As a safety consideration, it is desirable that the half life be relatively short so that, in the event of a catastrophe (such as loss of the source by explosion, melting, or oxidation), the area will not remain contaminated for long.

Chemical and physical properties must next be considered. Chemically, it is desirable that the source be inert chemically and metabolically. In the event the material is metabolized extreme caution in handling must be exercised to prevent, contamination and this requirement often will not be compatible with the other experimental requirements. Materials which are to be in contact with the flame should be chemically inert or should be encapsulated in a protective material. All materials in contact with flames should be cooled to prevent softening, attrition, or vaporization. The machinability of the material will be a factor for many applications, and it is important that adjacent components be fabricated of materials of similar properties to avoid thermal or mechanical difficulties.

The actual mass of the activity will often be quite small, and it will be necessary to support it on a carrier, in which case the radiological property of the carrier becomes important as a possible contaminant, in computing shielding requirements, and a possible contributor to the total effective radiation. Another important factor is the self-shielding of the source and any gamma radiation associated with it. The self-shielding characteristics will often require that the activity be increased to maintain the necessary effective ionization, and the latter factor presents the main external shielding problem.

All exhaust lines carrying combustion products must be provided with filters and must be monitored for contamination. In any operation where there is a danger of explosion, 
Table 1 Radiological properties of sources

\begin{tabular}{|c|c|c|c|c|c|}
\hline \multirow{2}{*}{$\begin{array}{l}\text { Source } \\
\operatorname{Pd}^{109}\end{array}$} & \multirow{2}{*}{$\begin{array}{l}\text { Half life } \\
13.1 \mathrm{hr}\end{array}$} & \multicolumn{2}{|c|}{$\begin{array}{c}\text { Radiation } \\
\text { type and energy }\end{array}$} & \multirow{2}{*}{$\begin{array}{l}\text { Daughter } \\
\text { product } \\
\qquad \mathrm{Ag}^{109}\end{array}$} & \multirow{2}{*}{$\begin{array}{l}\text { Principal hazards } \\
\text { External radiation }\end{array}$} \\
\hline & & $\beta^{-}$ & $0.95 \mathrm{Mev}$ & & \\
\hline $\mathrm{Au}^{198}$ & 2.69 days & $\left\{\begin{array}{l}\beta^{-} \\
\gamma\end{array}\right.$ & $\begin{array}{l}0.97 \mathrm{Mev} \\
0.411 \mathrm{Mev}\end{array}$ & $\mathrm{Hg}^{198}$ & \\
\hline$A u^{199}$ & 3.3 days & $\left\{\begin{array}{l}\gamma \\
\beta^{-} \\
\gamma\end{array}\right.$ & $\begin{array}{l}0.32 \mathrm{Mev} \\
0.23 \mathrm{Mev}(\max )\end{array}$ & $\mathrm{Hg}^{199}$ & External radiation \\
\hline $\mathrm{Cu}^{64}$ & $12.8 \mathrm{hr}$ & $\left\{\begin{array}{l}\beta^{-} \\
\beta^{+} \\
\gamma\end{array}\right.$ & $\begin{array}{l}0.57 \mathrm{Mev} \\
0.65 \mathrm{Mev} \\
1.34 \mathrm{Mev}\end{array}$ & $\begin{array}{l}\mathrm{Zn}^{64} \\
\mathrm{Ni}^{64}\end{array}$ & Contamination \\
\hline $\mathrm{Po}^{210}$ & 138.3 days & $\left\{\begin{array}{l}\alpha \\
\gamma \\
(\gamma)\end{array}\right.$ & $\begin{array}{l}5.3 \mathrm{Mev} \\
0.8\end{array}$ & $\mathrm{~Pb}^{206}$ & Contamination \\
\hline
\end{tabular}

the equipment should be located in an isolated area and emergency procedure preplanned and practiced.

Having selected a source, it is then necessary that the shielding and other safety requirements be examined with respect to the experimental needs. Special procedures for assembly and operation of the experimental equipment must then be devised. Each particular setup will present specific problems depending on the nature of the source and no general recommendations can be made. For illustrative purposes, we will consider the design of three specific installations which have been used or are in use at the present time.

\section{Specific Applications}

In this section, the general procedures outlined previously will be applied to three specific sources and applications. The materials to be considered are palladium-109, gold-198 and -199 (and copper-64), and polonium-210. The radiological properties of the materials are given in Table 1.

From the radiological safety standpoint these three source materials exemplify several different problems, which will be considered in turn.

\section{A Polonium-210}

Polonium-210 is an alpha emitter and decays to a stable isotope of lead. This material is extremely hazardous from the point of view of contamination, for several reasons.

1 It is an alpha emitter and can produce severe localized tissue damage if deposited in the body.

2 It is metabolized efficiently and incorporated into the bone structure on a long term basis.

3 It has a long half life (140 days) and can provide a continuous insult to tissue over a period of several years.

4 The extremely high particle energy (over $5 \mathrm{Mev}$ ) gives the parent nucleus such a recoil thrust that chunks of polonium are actually thrown into the air from a sample placed on a laboratory surface. Thus a whole room can become thoroughly and dangerously contaminated just by having a sample of polonium placed in it.

In view of these rather frightening aspects of this particular nuclide, one might well ask, when would the use of such a dangerous substance be justified? Some of its advantages should, therefore, be enumerated.

1 Because of its extremely short range in matter, essentially no protective shielding against external radiation is required.

2 The half life is long enough to permit leisurely, careful measurements in a fairly constant radiation field.

3 The extremely high rate of absorption makes possible efficient use of its tremendous energy within systems of reasonable size.

In practice, when these advantages are decisive, and the decision is made to proceed, the health hazards can be made negligible by suitable experimental design. Experiments with dangerous amounts of polonium-210 must be performed in completely enclosed, negative pressure systems, the exhausts of which are thoroughly filtered before release to the atmosphere. Only in this way can the extreme health hazards previously enumerated be obviated. With such precautions, work with high levels of alpha activity can be safely performed.

The polonium is to be used to study the mechanism of drag stabilized flames and the gross effects of radiation. Because of the excellent properties of polonium in regard to shielding and half life, it was felt that this material offers distinct advantages over other possible sources.

The equipment in which the polonium will be used is shown in Fig. 2. Polonium will be plated on a stainless steel flameholder and in this location can efficiently irradiate the reactor volume.

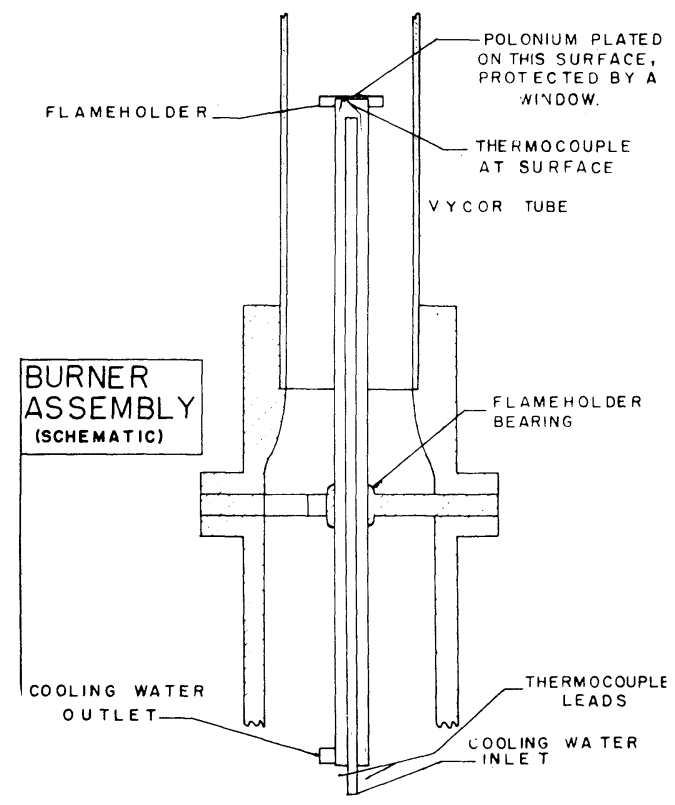

Fig. 2 Burner for use with $\mathrm{Po}^{210}$

Due to the possibility of contamination, the active surface is sealed by a very thin stainless steel window and the entire setup located in a dry box. Assembly will be made by means of rubber gloves located as an integral part of the dry box and, since the range of the radiation is short, no shielding is necessary. By means of windows located in the box, it will be possible to observe the flames and photograph them without the necessity of developing special techniques.

\section{B Palladium-109}

Palladium-109 is a beta emitter and decays to a stable isotope of silver. In the neutron production of palladium109, however, some palladium-111 is unavoidably produced. Fortunately, this isotope also is a beta emitter and decays 
through a beta-emitting isotope of silver to a stable isotope of cadmium. This material is much less hazardous than polonium-210 for several reasons.

1 It is a beta emitter and is much less of an internal hazard as the particles' energies are absorbed throughout much larger volumes.

2 It is chemically and metabolically inert and is not incorporated into the body structure except by mechanical means, such as insoluble particles being held in the nose or the lungs.

3 Since it has a short half life (14 hr), the degree of insult to tissue is reduced tremendously in a few days. Silver-111, which is always present in amounts several orders of magnitude less than palladium-109, has a larger half life (7 days) which is still much shorter than that of polonium-210.

It would appear that, because this material emits only beta particles, one could proceed with only a few centimeters of lucite for shielding. Because palladium is itself a heavy metal, however, the production of secondary electromagnetic radiation, Bremstrahlung, within the source material cannot be avoided. The amount of heavier shielding required to protect against this radiation will depend upon the geometric configuration of the source and holder, the material of the holder, and the maximum dosage levels acceptable.

The dosage rate outside the burner shown in the process of assembly in Fig. 3, due entirely to internal Bremstrahlung production, was so high as to require careful timing of necessary operations in order to prevent personnel overexposures.

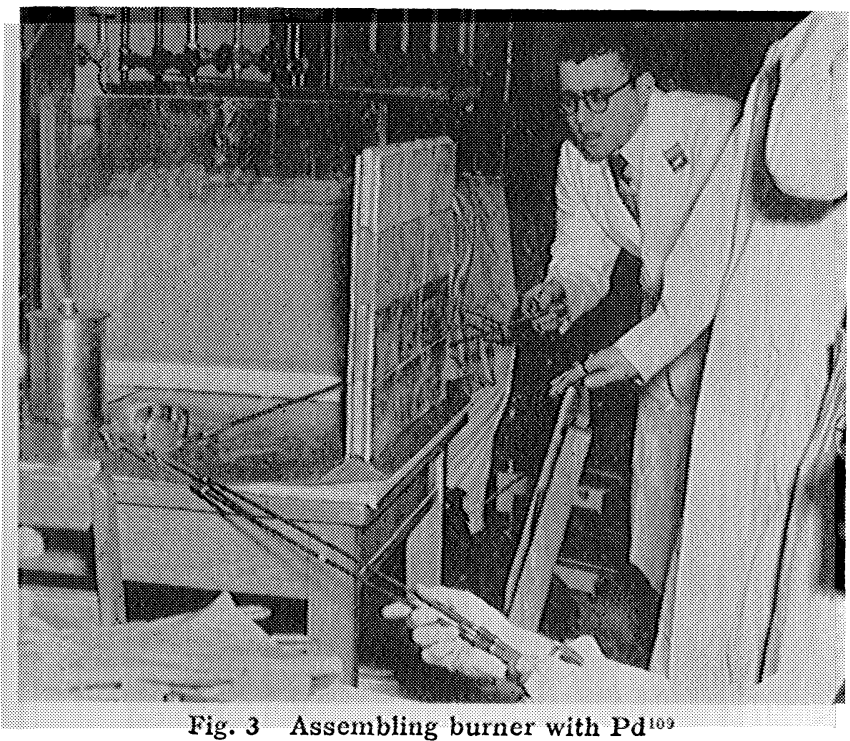

The equipment used in this work was a Bunsen burner, with removable nozzles and head assembly. The burner was located in a vacuum chamber equipped with windows. It was the purpose of this work to study the effect of beta radiation on Bunsen flames and flames stabilized on a spherical flameholder; the sources were in the form of a thin foil and an $1 / 8$-in. palladium sphere. These were located coaxially with the nozzle and on its axis, respectively, as shown in Fig. 4. By use of this assembly, it was possible to use the foil alone in the study of Bunsen flames and to use the foil and sphere to study stabilized flames.

The assembly operation for these sources required that the foil be clamped around the head and the assembled head transferred to the burner box and clamped in place. By use of the rather elongated tools shown in Fig. 3, and by careful manipulation, it was possible to place the foil in place and secure the burner without incident. The spherical flameholder was mounted on a wire in a simple frame, which fit into a groove on the upper edge of the nozzle. It was possible to place this piece in its proper location by means of tongs $3 \mathrm{ft}$ long.

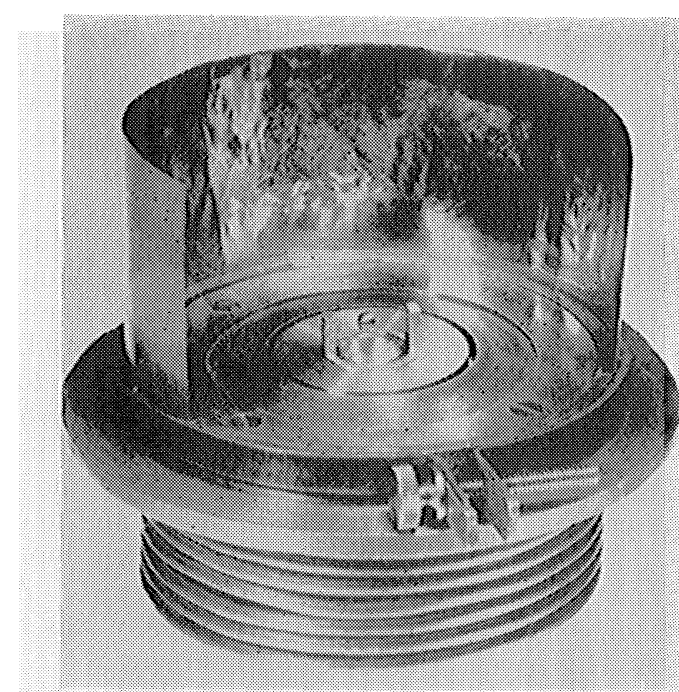

Fig. $4 \mathrm{Pd}^{109}$ sources in burner head

After the source was inside the burner box, its steel walls shielded much of the secondary $x$-radiation. The glass windows in the box presented less of a barrier to this radiation, and it was necessary that the operating personnel spend a minimum amount of time in front of the burner.

\section{Gold-198}

Gold-198 is a beta emitter which has an associated gamma emission and decays to a stable isotope of mercury. Some gold-199 is invariably produced along with the gold-198; however, both nuclides have similar emission characteristics and almost identical half lives.

This material, which is chemically and metabolically inert and has a half life of around three days, has the same advantages regarding internal hazard as has palladium-109.

The associated gamma emission, however, provides a serious external radiation hazard which must be considered when large quantities of material are to be handled.

Fig. 5 shows schematically the shielding required for safe, convenient operation of a gold-198 transfer. Five feet of water in the tank permitted direct visual unloading, and 3 $\mathrm{ft}$ of sand around the tank permitted safe operation in the vicinity of the tank after the water had been removed. The tank used in this work is shown, before the installation of shielding, in Fig. 6 .

It was the purpose of the study in which gold was used to ascertain the effect of beta radiation on a drag stabilized flame. Since the required data involved only the measurement of flow rates and pressures, it was possible for all operations to be conducted remotely.

The principal problem for this operation was the assembly

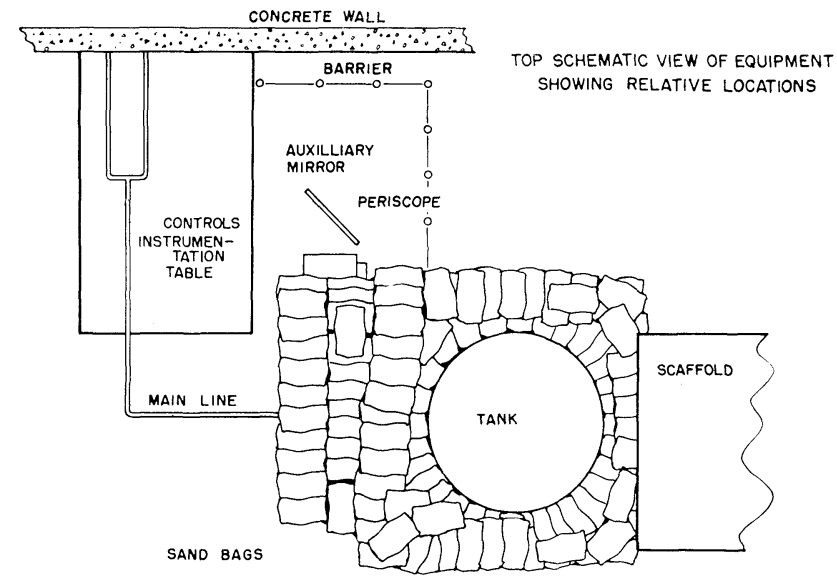

Fig. 5 Location of components for $\mathrm{Au}^{198}$ runs 
of the burner, which is shown schematically in Fig. 7. The body of the burner and flameholder assembly were located in the bottom of the tank and the tank filled with water which served as an optically transparent shield. The source was in the form of a hollow cylinder of gold bonded to copper to increase its strength. Because of the high gamma level associated with this source, it was necessary that it be shipped in a massive lead cask and that all operations be conducted behind adequate barriers. To transfer the source, the shipping container was immersed under water, the lid removed, and the gold removed from the cask by means of long tongs. Following the removal of the cask from the water, the source was lifted by means of internal tongs to its groove in the burner wall, as shown in Fig. 8. Fig. 9 shows the gold cylinder in position. To hold the gold in place and to complete the burner assembly, the removable burner top was screwed in place by a special tool, as shown in Fig. 10. After connection of cooling lines, the burner assembly was complete. (Fig. 11 is a view of the assembled burner.)

Following this assembly, the tank lid was bolted in place and the water drained.

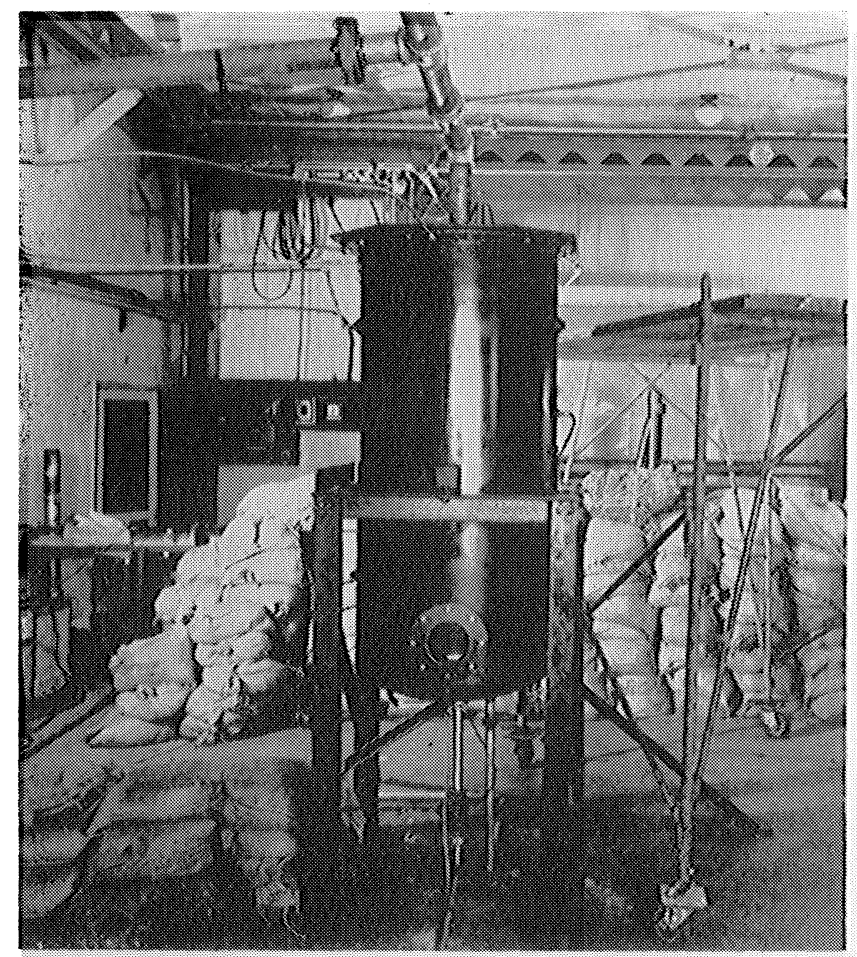

Fig. 6 Tank for use with $A u^{1 * 8}$

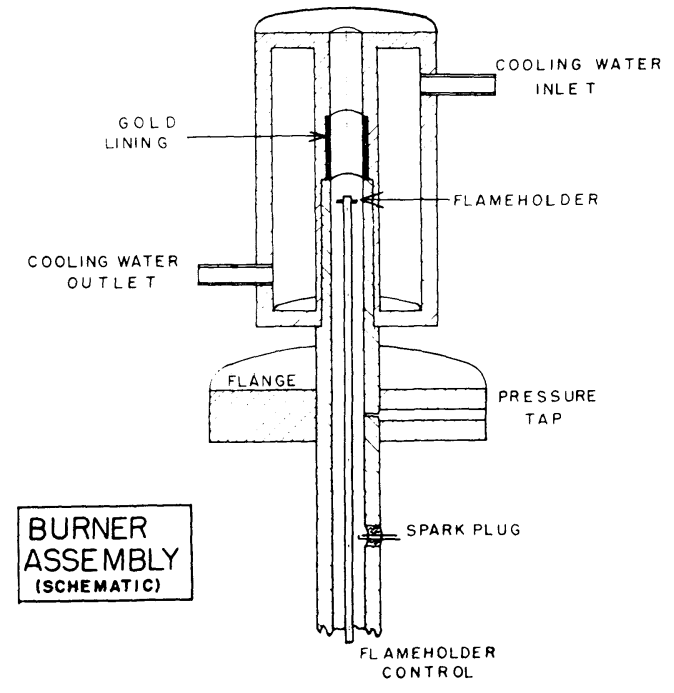

Fig. 7 Burner for use with $\mathrm{Au}^{198}$
Because of the design of this equipment, it was possible to obtain data without seeing the flame. A periscope was provided for observation of the burner as an additional safeguard.

The three types of assemblies considered illustrate some of

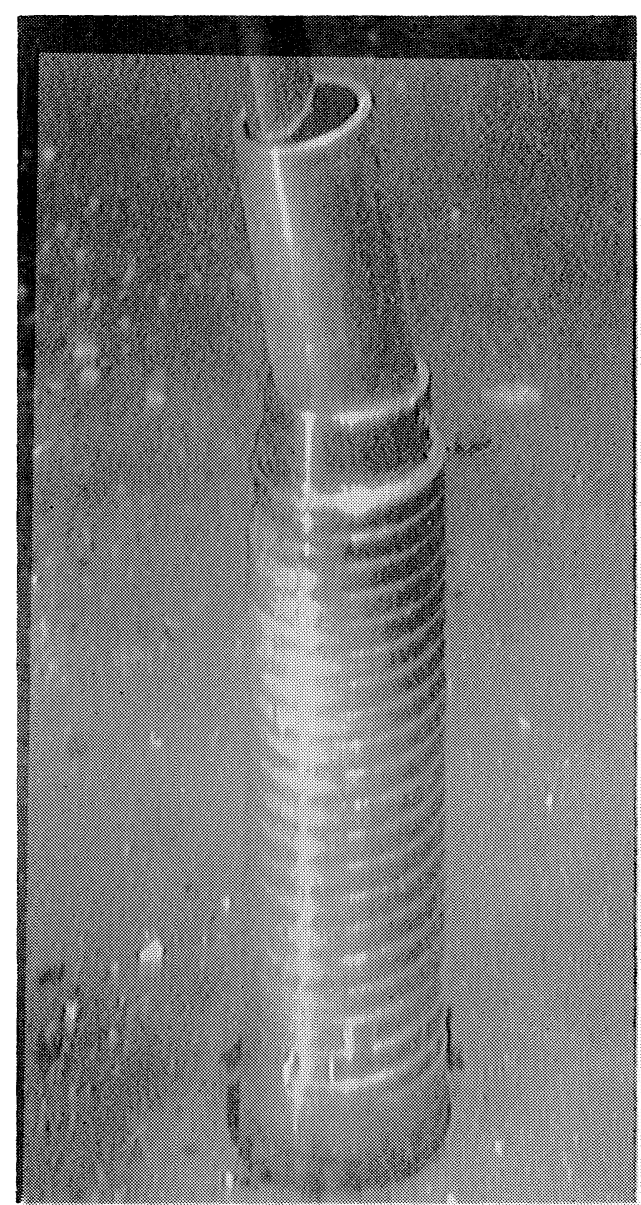

Fig. 8 placing Au ${ }^{148}$ source in place

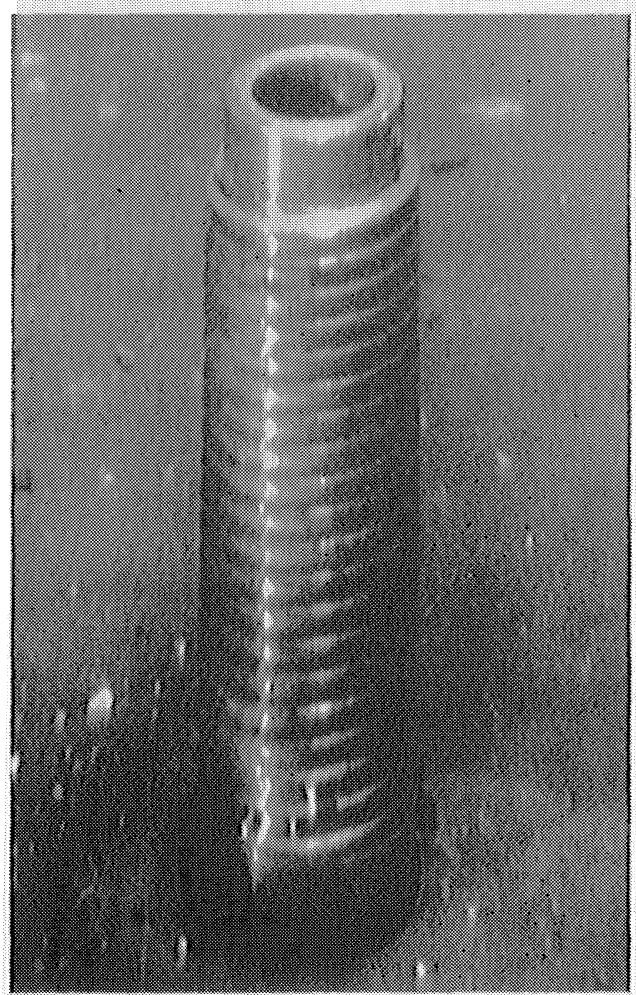

Fig. 9 Aut:8 source in place 
the problems which one must face and solve. It is most important in any contemplated operation of this type that each stage in the planning and execution be done as a cooperative venture of the research worker and radiological safety personnel.

Although it has been shown experimentally that nuclear radiation may lead to improved combustion, the authors feel that is is somewhat premature to consider applications to power plants. However, the use of nuclear radiation as a tool in combustion research offers opportunities for studies in which the worker may vary at will factors which affect the kinetics of combustion, without changing the hydrodynamics of combustion, and so gain insight into the mechanism of combustion processes. The paucity of fundamental data in combustion is apparent to workers in this field and any contribution which adds to combustion science and technology should prove helpful.

The authors wish to acknowledge the financial support for this work of the University of Michigan Memorial-Phoenix Project and the U. S. Atomic Energy Commission. Alexander Weir, Jr., of the Aircraft Propulsion Laboratory, suggested some of the equipment design used in the work with $\mathrm{Pd}^{109}$.

\section{References}

1 Brownell, L. E., et al., "Utilization of the Gross Fission Products," Progress Reports 2, 3, 4, 5, Project 1943, Engineering Research Institute, University of Michigan, Ann Arbor, Mich.

2 Gluckstein, M. E., and Cullen, R. E., "Effect of Beta Radiation on Combustion of Hydrocarbon-Air Mixtures," Fifth Symposium (International) on Combustion, Reinhold, New York, 1955.

3 Goldstein, H., et al., "Interim Report on the NDA-NES Calculations of Gamma Ray Penetration," NDA News 15C-20, Sept., 1953.

4 Jost, W., "Explosion and Combustion Processes in Gases," MeGraw-Hill, New York, 1946.

5 Kinsman, S., et al., "Radiological Health Handbook," Sanitary Engineering Center, Cincinnatti, Ohio.

6 Lewis, B., and von Elbe, G., "Combustion, Flames and Explosions," Academic Press, New York, 1951.

7 Steacie, E. W. R., "Atomic and Free Radical Reactions," ACS Monograph 125, Reinhold, New York, 1954.

\section{Improved On-Off Missile Stabilization}

(Continued from page 648)

Equations," Quarterly of Applied Mathematics, to appear.

2 bis Bass, R. W., "Equivalent Linearization, Nonlinear Circuit Synthesis, and the Stabilization and Optimization of Control Systems," Proceedings, Second Symposium on Nonlinear Circuit Analysis, Polytechnic Institute of Brooklyn, to appear in Oct. 1956. Preprints now available on request.

3 Bellman, R., "Stability Theory of Differential Equations," McGraw-Hill, 1953.

4 Bellman, R., "The Stability Theory of Differential-difference Equations," The Rand Corporation, P-381, 1953, pp. 1-27.

5 Bellman, R., and Danskin, J. M., Jr., "The Stabiiity Theory of Differential Difference Equations," Proceedings, Symposium on Nonlinear Circuit Analysis, Polytechnic Institute of Brooklyn, 1953, pp. 107-123.

6 Bellman, R., (with the assistance of Danskin, J. M., Jr.), "A Survey of the Mathematical Theory of Time-lag, Retarded Control, and Hereditary Processes," The Rand Corporation, Santa Monica, Calif., 1954

6 bis Myschkis, A. D., "Lineare Differentialgleichungen mit

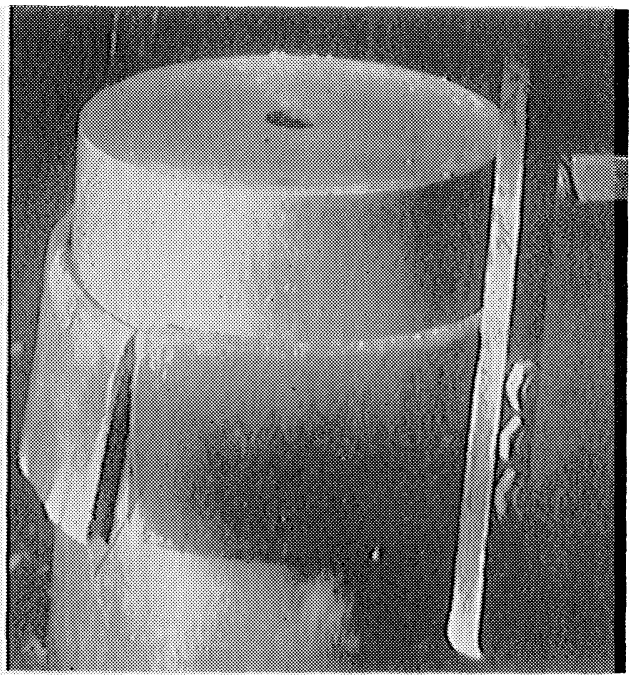

Fig. 10 Place head in place for Auts operations

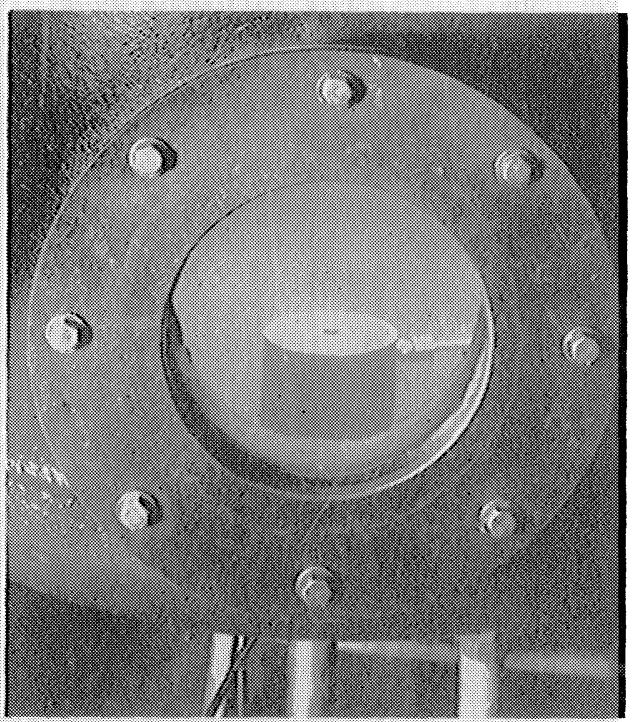

Fig. 11 Completed burner for $A u^{1 * 6}$ operations

nacheilendem Argument," Deutscher Verlag der Wissenschaften, Berlin, 1955 .

7 Coddington, E. A., and Levinson, N., "Theory of Ordinary Differential Equations," McGraw-Hill, 1955.

8 Felt, N. E., Jr., "Development of a Stabilization System for the Viking Rocket," Jet Propulsion, vol. 25, 1955, pp. 392395.

9 Flügge-Lotz, I., "Discontinuous Automatic Control," Princeton University Press, 1953.

10 Lawden, D. F., "Mathematics of Engineering Systems (Linear and Non-Linear)," Methuen, London, 1954.

11. Lefschetz, S., "Lectures on Differential Equations," Annals of Mathematics Studies, no. 14, Princeton University Press, 1946.

12 McDonald, D. C., "Intentional Nonlinearization of Servomechanisms," Proceedings Symposium on Nonlinear Circuit Analysis, Polytechnic Institute of Brooklyn, 1953, pp. 402-411.

13 Minorsky, N., "Control Problems," Journal of the Franklin Institute, vol. 232, 1941, pp. 451-487, 519-551.

14 Crocco, L., and Cheng, S.-I., "Theory of Combustion Instability in Liquid Propellant Rocket Motors," Butterworths Scientific Publications, London, 1956.

15 Tsien, H. S., "Engineering Cybernetics," McGraw-Hill, 1954 .

16 Weiss, H. K., "Analysis of Relay Servomechanisms," Journal of the Aeronautical Sciences, vol. 13, 1946, pp. 364-376. 